\title{
Primary Tumor Thickness as a Prognostic Factor in Merkel Cell Carcinoma: The Next Big Thing?
}

\author{
Vernon K. Sondak, MD ${ }^{1,2}$, Jonathan S. Zager, MD ${ }^{1,2}$, and Jane L. Messina, MD ${ }^{1,3}$ \\ ${ }^{1}$ Department of Cutaneous Oncology, Moffitt Cancer Center, Tampa, FL; ${ }^{2}$ Departments of Oncologic Sciences and \\ Surgery, University of South Florida, Tampa, FL; ${ }^{3}$ Departments of Pathology \& Cell Biology and Dermatology, University \\ of South Florida, Tampa, FL
}

Fifty years ago, there was a cutaneous malignancy that was rapidly increasing in incidence and beginning to receive serious scrutiny by surgical oncologists, dermatopathologists, and dermatologists. It nearly always presented at a locally advanced stage with an expectation of a poor outcome. Prognostic factors were poorly understood, so the occasional patient with advanced disease who defied expectations and survived long-term was a notable and mysterious case. Controversy surrounded the management of the regional lymph nodes, despite recognition that they were frequently the first (and sometimes the only) site of metastatic involvement-in part because of pessimism that distant dissemination of tumor had already occurred and hence treating the nodes was a futile effort. The name of this malignancy? Melanoma.

So what changed over the past 5 decades? One of the most significant advances in understanding the prognosis of melanoma came in 1969, when Wallace Clark and colleagues called attention to the prognostic significance of the level of tumor invasion into the dermis. ${ }^{1}$ Soon thereafter, Alexander Breslow introduced the micrometer measurement of tumor thickness that now bears his name. ${ }^{2}$ Importantly, Breslow showed that tumor thickness was a better prognostic marker than Clark's levels of invasion or measured tumor diameter, while noting that "in general all measurements of tumor size increased with the stage of invasion, but there was a great deal of overlap." 2

This is an Editorial commentary regarding the article by Lim et al. doi:10.1245/s10434-012-2509-x.

(C) Society of Surgical Oncology 2012

Published Online: 24 July 2012

V. K. Sondak, MD

e-mail: vernon.sondak@moffitt.org
Unfortunately, in 1970, relatively few melanomas were diagnosed at the earliest stages of thickness and invasion that portended a favorable prognosis. A second transformational event was the introduction of easily understandable and applicable diagnostic criteria for identifying pigmented lesions suspicious for representing early melanoma (and hence requiring biopsy) — the ABCD criteria. ${ }^{3,4}$ Increasingly, melanomas were diagnosed at an early stage where the expectation was for an excellent outcome, and those few patients who developed distant disease were an exception to the norm. Indeed, outcomes quickly improved to the point that aggressive surgical management of the regional nodes became controversial because of the perception that most patients would not have evidence of metastasis and hence were being subjected to morbidity without prospect of benefit. Of course, this set the stage for the third revolutionary development-sentinel lymph node biopsy. ${ }^{5}$ At last, melanomas with early dissemination to the regional nodes could be reliably identified and treated, and the number of cases with truly unexpected outcomes dramatically decreased. Even with recognizing how far we have come in this disease, thick melanomas are still a major challenge, especially in elderly patients. Once a melanoma exceeds $4 \mathrm{~mm}$ in thickness, while ulceration and sentinel node status retain prognostic importance, our ability to predict which patients will do well or poorly is fairly limited. Nonetheless, the recognition of the clinical significance of that $4 \mathrm{~mm}$ thickness cutoff has unequivocally improved our understanding of the natural history of melanoma.

Today, there is another cutaneous malignancy, Merkel cell carcinoma, that is rapidly increasing in incidence and beginning to receive serious scrutiny by surgical oncologists, dermatopathologists, and dermatologists. It nearly always presents at a locally advanced stage, usually in 
elderly patients and often in those with substantial comorbidities. Prognostic factors are poorly understood, and controversy surrounds the management of the regional lymph nodes, despite recognition that they are frequently the first (and sometimes the only) site of metastatic involvement. In many ways, Merkel cell carcinoma is highly analogous to thick melanoma: most lesions are thick and deeply invasive, regional nodal metastases are commonly identified, and distant dissemination has already occurred at the time of diagnosis in many patients. With Merkel cell carcinoma, there is a critical lack of reliable recognition features for "early" diagnosis. ${ }^{6,7}$ Interestingly, sentinel node biopsy has been widely adopted by many surgical oncologists and even incorporated into the latest staging system, ${ }^{8}$ although considerable uncertainty about its prognostic significance remains. One important difference between Merkel cell carcinoma and thick melanoma that should not be overlooked is the far greater responsiveness of Merkel cell carcinoma to both radiation and cytotoxic chemotherapy, which makes multimodality management a key consideration even for elderly and infirm patients.

As with melanoma decades ago, progress in Merkel cell carcinoma today is clearly hampered by our lack of understanding of the most important prognostic factors. We can no longer blame its rarity, as we have a more better understanding of many cancers far less common. We can and indeed must learn from our experience with thick melanoma. The time has come for systematic assessment and recording of histopathologic factors potentially influencing outcome in Merkel cell carcinoma, to enable largescale retrospective evaluations of the sort that produced such progress in melanoma. Of these, tumor thickness should become part of the routine histopathologic evaluation of all primary Merkel cell carcinomas, not an "optional" item as suggested by the College of American Pathologists. ${ }^{9}$ We make this statement not because thickness is a proven prognosticator, but because this is the best way to validate or refute it as a prognosticator. Correlating sentinel node biopsy status with thickness (nodal status has shown only poor correlation with tumor diameter) may help elucidate the biologic significance of tumor thickness even in patients who ultimately die from comorbid conditions and not their Merkel cell carcinoma. ${ }^{10,11}$ For any prognosticator to be successful, we must define appropriate cutoffs. Lim et al. looked at $10 \mathrm{~mm}$ tumor thickness as a cutoff and found particularly poor survival for patients with Merkel cell carcinomas thicker than $10 \mathrm{~mm} .{ }^{12}$ However, harken back to melanoma for a moment: Patients with melanomas thicker than $10 \mathrm{~mm}$ probably also have a particularly poor survival, yet that is not a cutoff we would consider optimal. It is certainly possible that $4 \mathrm{~mm}$ is a better thickness discriminator between those Merkel cell carcinomas with a poor prognosis and those with an intermediate (not necessarily a good) prognosis. It may be that only Merkel cell carcinomas thinner than $1 \mathrm{~mm}$ have a "good" prognosis; in our experience, such thin Merkel cell tumors are currently quite rare (we still lack that third transformational event-improved early recognition of this disease).

Several additional points bear emphasis: Tumor diameter is a relatively inaccurate measurement compared with micrometer thickness and often difficult to ascertain retrospectively. ${ }^{13}$ Compared with melanomas, however, Merkel cell carcinomas are more often round in shape, meaning diameter and thickness may correlate more closely. Even if thickness proves superior to diameter, thickness alone will likely not be a perfect prognosticator-we rely on ulceration and mitotic rate as well as thickness in melanoma. For Merkel cell carcinoma, mitotic rate is problematic_-it is almost always high, so what cutoffs if any provide independent predictive information? Ulceration is not an established prognosticator for Merkel cell carcinoma, but perhaps angiolymphatic invasion, shown by some to correlate with sentinel node status and survival, plus thickness would be more informative? ${ }^{14}$ Studies to date have been inconsistent regarding the prognostic significance of detecting Merkel cell polyomavirus DNA in the tumor or antibodies in the serum, but the clear etiologic role and potential therapeutic implications make further investigation of the prognostic significance of Merkel cell polyomavirus infection of paramount importance. ${ }^{15-17}$ Finally, although there are clearly other potential prognosticators worth investigating, until we have a good handle on the prognostic significance of the factors already mentioned in large, prospectively evaluated populations, it will be difficult if not impossible to ascertain their independent contribution to any clinically relevant outcome. $^{18,19}$ However, here again it is imperative to obtain as much prospective data as we can to allow those investigations to take place.

So how important is tumor thickness as a prognostic factor in Merkel cell carcinoma? Determining the answer to that question will be an essential step forward in making progress in this disease, and the knowledge gained in the process may well prove to be even more important than the actual answer.

\section{REFERENCES}

1. Clark WH Jr., From L, Bernardino EA, Mihm MC. The histogenesis and biologic behavior of primary human malignant melanomas of the skin. Cancer Res. 1969;29:705-26.

2. Breslow A. Thickness, cross-sectional areas and depth of invasion in the prognosis of cutaneous melanoma. Ann Surg. 1970; 172:902-8. 
3. Friedman RJ, Rigel DS, Kopf AW. Early detection of malignant melanoma: the role of physician examination and self-examination of the skin. CA Cancer J Clin. 1985;35:130-51.

4. Abbasi NR, Shaw HM, Rigel DS, Friedman RJ, McCarthy WH, Osman I, et al. Early diagnosis of cutaneous melanoma. Revisiting the ABCD criteria. JAMA. 2004;292:2771-6.

5. Morton DL, Wen DR, Wong JH, Economou JS, Cagle LA, Storm FK, et al. Technical details of intraoperative lymphatic mapping for early stage melanoma. Arch Surg. 1992;127:392-9.

6. Heath M, Jaimes N, Lemos B, Mostaghimi A, Wang LC, Peñas $\mathrm{PF}$, et al. Clinical characteristics of Merkel cell carcinoma at diagnosis in 195 patients: the AEIOU features. J Am Acad Dermatol. 2008;58:375-81.

7. Lien MH, Glass LF, Fenske NA. Clinical recognition and diagnosis of Merkel cell carcinoma. In: Sondak VK, Messina JL, Zager JS, Deconti RD, editors. Merkel cell carcinoma: a multidisciplinary approach. London: Imperial College Press; 2011: 119-29.

8. Lemos BD, Storer BE, Iyer JG, Phillips JL, Bichakjian CK, Fang $\mathrm{LC}$, et al. Pathologic nodal evaluation improves prognostic accuracy in Merkel cell carcinoma: analysis of 5823 cases as the basis of the first consensus staging system. J Am Acad Dermatol. 2010;63:751-61.

9. Rao P, Balzer BL, Lemos BD, Liegeois NJ, McNiff JM, Nghiem $\mathrm{P}$, et al. Protocol for the examination of specimens from patients with Merkel cell carcinoma of the skin. Arch Pathol Lab Med. 2010;134:341-4.

10. Schwartz JL, Griffith KA, Lowe L, Wong SL, McLean SA, Fullen DR, et al. Features predicting sentinel lymph node positivity in Merkel cell carcinoma. J Clin Oncol. 2011;29:1036-41.
11. Sarnaik AA, Zager JS, Cox LE, Ochoa TM, Messina JF, Sondak VK. Routine omission of sentinel lymph node biopsy for Merkel cell carcinoma $\leq 1 \mathrm{~cm}$ is not justified. J Clin Oncol. 2010;28;e7.

12. Lim CS, Whalley D, Haydu LE, et al. Increasing tumor thickness is associated with more frequent recurrence and poorer survival in Merkel cell carcinoma patients. Ann Surg Oncol. 2012; this issue.

13. Zager JS, Rollison DE, Messina J. Prognostication in Merkel cell carcinoma. Expert Rev Anticancer Ther. 2011;11:665-7.

14. Fields RC, Busam KJ, Chou JF, Panageas KS, Pulitzer MP, Allen $\mathrm{PJ}$, et al. Five hundred patients with Merkel cell carcinoma evaluated at a single institution. Ann Surg. 2011;254:465-73.

15. Touze A, Le Bidre E, Laude H, Fleury MJ, Cazal R, Arnold F, et al. High levels of antibodies against Merkel cell polyomavirus identify a subset of patients with Merkel cell carcinoma with better clinical outcome. J Clin Oncol. 2011;29:1612-9.

16. Sihto H, Kukko H, Koljonen V, Sankila R, Böhling T, Joensuu H. Merkel cell polyomavirus infection, large $\mathrm{T}$ antigen, retinoblastoma protein and outcome in Merkel cell carcinoma. Clin Cancer Res. 2011;17:4806-13.

17. Handschel J, Müller D, Depprich RA, Ommerborn MA, Kübler $\mathrm{NR}$, Maujoks $\mathrm{C}$, et al. The new polyomavirus (MCPyV) does not affect the clinical course in MCCs. Int J Oral Maxillofac Surg. 2010;39:1086-90.

18. McCardle TW, Sondak VK, Zager J, Messina JL. Merkel cell carcinoma: pathologic findings and prognostic factors. Curr Prob Cancer. 2010;34:47-64.

19. Knapp C, Zager JS, Messina JL, Sondak VK. New prognostic factors in Merkel cell carcinoma. In: Sondak VK, Messina JL, Zager JS, Deconti RD, editors. Merkel cell carcinoma: a multidisciplinary approach. London: Imperial College Press; 2011:143-58. 